\title{
EXPERIMENTS AND COMPUTATIONAL PARTICLE FLUID DYNAMICS SIMULATIONS OF BIOMASS GASIFICATION IN AN AIR-BLOWN FLUIDIZED BED GASIFIER
}

\author{
RAMESH TIMSINA, RAJAN K. THAPA, BRITT M.E. MOLDESTAD \& MARIANNE S. EIKELAND \\ Department of Process, Energy and Environmental Technology, University of South-Eastern Norway, \\ Porsgrunn, Norway
}

\begin{abstract}
Experiments were performed in a pilot-scale bubbling fluidized bed gasification reactor with air as a fluidizing agent. Birch wood chips and sand particles were used as biomass and bed materials. Average molar product gas composition was 0.214 of $\mathrm{CO}, 0.212$ of $\mathrm{CO}_{2}, 0.103$ of $\mathrm{H}_{2}, 0.074$ of $\mathrm{CH}_{4}$ and 0.397 of $\mathrm{N}_{2}$. A kinetics-based model was developed for the gasification process and simulated using commercial software Barracuda ${ }^{\circledR}$. The model is validated against the measured gas compositions. The validated model was used to study the product gas compositions for olive waste and straw pellets. The effects of equivalence ratio (ER) on the product gas composition for birch wood was also studied in one of the simulations. Birch wood gave the highest $(20.5$ mole \%) CO production rate and lowest $(9.0$ mole \%) $\mathrm{H}_{2}$ production rate. The product gas flow rate was $1.96 \mathrm{Nm}^{3}$ per $\mathrm{kg}$ of biomass and the lower heating value of the product gas was $6.65 \mathrm{MJ} / \mathrm{Nm}^{3}$. The $\mathrm{CO}$ concentration decreased from 25 to $13.2 \mathrm{~mole} \%$, whereas $\mathrm{CO}_{2}$ concentration increased from 17 to 19.5 mole \% when increasing ER from 0.2 to 0.3 . The $\mathrm{CO}$ and $\mathrm{H}_{2}$ concentrations for the olive waste were 8.1 and 56.1 mole \%. The $\mathrm{CO}$ and $\mathrm{H}_{2}$ concentrations for the straw pellets were 6 and 73.4 mole \%.

Keywords: air-blown, biomass gasification, bubbling bed, CPFD, MP-PIC approach.
\end{abstract}

\section{INTRODUCTION}

European Union has an energy policy to achieve $20 \%$ share of the renewable energy in total energy consumption, a reduction of $20 \%$ greenhouse gas emissions and $20 \%$ improvements in the efficiency of biomass-based conversion technologies by 2020 (EU 20-20-20). The policy shows the great importance of the renewable energy [1]. Among the renewable energy sources, biomass has a huge potential to fulfil the future energy demands in the world. Biomass is not only geographically distributed with abundant availability [2] but also mitigates climate change.

Among the different alternatives to convert the biomass into biofuels, biomass gasification is one of the attractive routes. Biomass gasification is the partial oxidation of the carbonaceous fuels (biomass) into syngas (a mixture of mainly $\mathrm{CO}$ and $\mathrm{H}_{2}$ ) in the presence of air, oxygen and/or steam [3]. The gasification process converts biomasses such as wood chips, agricultural waste, etc. into high-energy product gas. The products of the gasification are used to produce the second-generation biofuels and chemicals. The product gas can also be used to produce electricity and heat in a heat and power plant. The produced biofuels can be integrated into the existing infrastructure [4]. The gasification technology can be integrated into existing conventional power plants to increase the efficiency [5].

Fluidized bed reactors are commonly used for biomass gasification due to the uniform gas-solid mixing. The uniform mixing gives the homogeneous reactor temperature. Although gas cleaning is required after the gasifier, fluidized bed gasification reactor has the potential for scaling up the gasification system at relatively low costs. The gasification temperature is comparatively low $\left(700-900^{\circ} \mathrm{C}\right)$, which avoids the issue of agglomeration and sintering of 
the ash. Fluidized beds have high efficiency, are relatively simple to control and have a wide range of operating conditions compared to other thermal conversion technologies [3].

There are different steps in bubbling fluidized bed biomass gasification. Biomass undergoes pyrolysis/devolatilization, partial oxidation, char gasification, tar conversion and water gas shift reaction during the gasification process. The processes depend strongly on the fuel properties, the gasifying agent, the bed material and operational properties such as temperature, pressure and biomass feed rate. These are the key parameters for optimal design and operation of the biomass gasification reactor.

Due to experimental setup limitations, it is difficult to study the effect of the different parameters on the biomass gasification. The problems can be minimized by using a validated computational model. Modelling and simulation of biomass gasification in a bubbling fluidized bed reactor is complex as it involves solid-gas and solid-solid interactions along with the chemical transformation in the reactor [6]. Kinetics-based models are complex and are based on the conservation of mass, momentum and energy of the involved particles. However, during the past few decades, there has been a significant progress in this field. Bubbling fluidized bed gasifiers involve multiphase flow along with various chemical and physical transformations and heat and mass transfer.

Modelling of multiphase flow systems are challenging due to the coupling of turbulent gas flow and particle motions together with inter-particle collisions. The basic approaches for modelling of the gas-solid multiphase system are Eulerian-Eulerian and Eulerian-Lagrangian. In the Eulerian-Eulerian approach, conservation laws and the turbulence of both solid and fluid particles are solved with Navier-Stokes equation considering them as a continuous phase. The main disadvantage of this method is the lack of detailed transient information of the two-phase interactions [7]. In the Eulerian-Lagrangian approach, fluid particles are treated as the continuous phase and the solid particles are treated as a discrete phase. The fluid particles are solved by Navier-Stokes equations and the solid particles are solved with the Newton's equation of motion. There is strong coupling between the two phases. EulerianLagrangian approach gives high loading to a computer central processing unit due to the huge number of particles in the system and the requirement of the small time step for solving the particle collisions [6].

MP-PIC modelling is developed from the Eulerian-Lagrangian approach, which reduces the computational costs related to the discrete modelling of the solid particles. Computational particles for MP-PIC modelling is a group of particles (called parcels) with similar properties such as size, density, residence time, velocity, etc. This eliminates the need for tracking of the individual particles. The parcels are modelled in a discrete frame and the particle interactions are modelled in Eulerian frame. Hence, the particles are solved both in Eulerian and Lagrangian frame, correlated by an interpolation functions [8]. The fluid particles are solved with an Eulerian approach. Barracuda VR is a commercial software based on the MP-PIC modelling, also known as the computational particle fluid dynamics (CPFD). The strong coupling between fluid and particle phase gives a high level of accuracy and fast computational time in Barracuda. The rapid development of the graphic process unit in computers has made the CPFD simulation capable of simulating the real process in short time.

Guo et al. [9] have carried out experiments with wood powder (particle size of less than $250 \mu \mathrm{m})$ with air as a gasifying medium. An autothermal gasifier was used to study the gasification temperature, gas yield, gas composition, heating value and gasification efficiency for different equivalence ratio (ER) and biomass particle sizes. The gas temperature and $\mathrm{H}_{2}$ production increased with increase in ER. The gas yield, heating value and gasification efficiency 
increased with a decrease in biomass particle size [9]. Lv et al. [10] also showed that smaller particles are favourable to obtain higher gas yield and heating value of the product gas. Introduction of the steam in air gasification of biomass improved the gas quality [10]. The current study involves the gasification of birch wood chips with particle sizes in the range of 1-15 $\mathrm{mm}$, which reduces the cost related to the preparation of the feedstocks.

Li et al. [11] have studied the air-blown biomass gasification in a circulating fluidized bed reactor. Results from the developed equilibrium model based on Gibbs free energy deviates due to the limitations of the reaction kinetics in the model. The model was tuned by adjusting the amounts of unconverted carbon and methane. The tuned model gave the product gas compositions, cold gas efficiency and the heating value of the product gas close to the experiment [11]. The simulation results agreed well with the experimental results using the reaction kinetics involved in air gasification of biomass in this study.

There are many CFD/CPFD models reported in the literature for steam gasification of biomass and coal [12-15]. However, no previous work was found for the modelling of air gasification of biomass in a bubbling fluidized bed reactor using CPFD approach. Simulations were performed using Barracuda VR 17.4.1 version. The main objective of the simulations is to study the effect of ER and the biomass feed on the performance of the gasifier.

\section{EXPERIMENTAL SETUP}

The experiments were carried out in a bubbling fluidized bed gasification reactor with a fuel capacity of $20 \mathrm{~kW}$ located at the University of South-Eastern Norway. The reactor used for the experiment is presented in Fig. 1. The reactor consists of a stainless steel cylindrical reactor (D) with $100 \mathrm{~mm}$ internal diameter, height of $1 \mathrm{~m}$ above the air distributor and wall thickness of $4 \mathrm{~mm}$. An electric heating coil is attached to the outer surface of the reactor. The inner surface of the reactor is coated with refractory material, whereas the outer surface is insulated with thick fiberglass. Before starting the experiments, the fuel silo $(\mathrm{C})$ is filled with biomass and sealed properly. The fuel is supplied through twoscrew conveyors $B_{1}$ and $B_{2}$. The schematic block diagram of the screw conveyors can be found in [16].

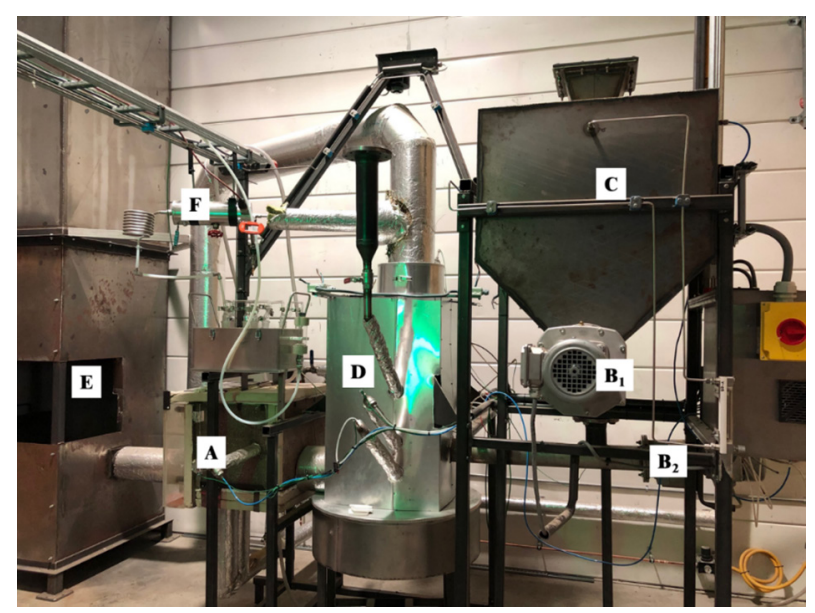

Figure 1: Experimental setup for bubbling fluidized bed. 


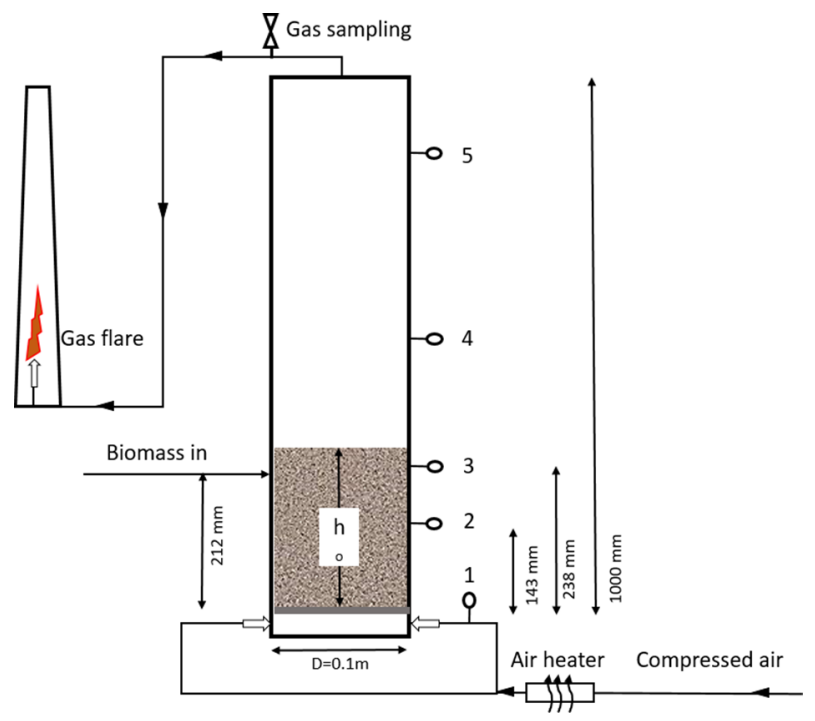

Figure 2: Schematic block diagram of the bubbling fluidized bed gasification reactor: points 1-5 indicate pressure and temperature sensor probe and $h_{0}$ is the initial bed height.

Fig. 2 shows the schematic diagram of the gasification reactor, where the exact location of the different sensors and the biomass feeding position are illustrated. The temperature and pressure sensors are located at five different positions along the height of the reactor. The temperature and pressure sensors provide the real-time measurements in a computer program available at the experimental facility. The pressure sensor measures the gauge pressure at the given position. The air flow rate is measured by BROOK air flowmeter with an operating range of $0.48-4.7 \mathrm{~kg} / \mathrm{h}$. There is a gas sampling location $(\mathrm{F})$ just outside of the reactor. The product gas passes through the gas transmission line for combustion into the flare (E). There is an air heater (A) that heats up the gasifying air to a temperature around $450^{\circ} \mathrm{C}$. The heated air is introduced into the bed just below the gas distributor plate.

Experiments were performed using birch wood chips of an irregular shape and with length ranges from 1 to $15 \mathrm{~mm}$. The proximate analysis of the chips is presented in Table 1. Sand with an average particle diameter of $285 \mu \mathrm{m}$ was used as bed material during the experiments. The initial bed height was $250 \mathrm{~mm}$. The diameter of the sand particles was in the range of $100-425 \mu \mathrm{m}$. The composition of the pyrolysis gases (volatiles) from the different biomasses is presented in Table 1 .

Table 1: Proximate analysis and pyrolysis gas compositions for different biomass.

\begin{tabular}{llllllll}
\hline & & & \multicolumn{5}{c}{$\begin{array}{l}\text { Pyrolysis gas compositions (molar } \\
\text { Praction) }\end{array}$} \\
\hline & Proximate 28] \\
Ash & $F C$ & $V M$ & $\mathrm{CH}_{4}$ & $\mathrm{CO}$ & $\mathrm{CO}_{2}$ & $\mathrm{H}_{2}$ \\
Birch wood & 1.16 & 18.84 & 80 & 12.13 & 68.56 & 17.64 & 1.67 \\
Straw pellets & 9.8 & 11.2 & 79 & 8.00 & 48.4 & 4.7 & 38.9 \\
Olive waste & 7.17 & 25.48 & 67.35 & 18.3 & 47.8 & 12.3 & 21.6 \\
\hline
\end{tabular}




\section{COMPUTATIONAL MODEL}

A CPFD model was developed using the Barracuda software to simulate the gasification process. The reactor was modelled as an open cylinder. A cylinder with inner diameter of $0.1 \mathrm{~m}$ and height of $1 \mathrm{~m}$ was drawn using the CAD software and the drawing was imported into Barracuda. The total number of cells were specified before generating the grid on the imported geometry. The grids act as control volumes, where the Barracuda solver solves the governing equations. The computational grid, initial bed conditions and boundary conditions are presented in Fig. 3 .

A mesh with 3577 real computational cells was used. The properties of components in the product gas, air and sand particles were imported from the available database in Barracuda. The Wen-Yu drag model was used with $60 \%$ momentum loss after the particle collision. The blended acceleration model was activated as the particle mixtures have different sizes and densities. The normal and tangential coefficients of the particle-wall interaction were set to a default value of 0.3 and 0.99 , respectively. Normal and tangential coefficients give the fraction of the normal and tangential components of the particle momentum, which is retained by the particle after collision with the wall. Particles moving towards a region of the close packed bed will be rerouted randomly based on particle normal stress function and the particle incident angle. Maximum momentum redirection from the collision was set to $40 \%$ of the original value.

Volatiles matter, char and ash composition of the biomass feed were specified according to Table 1 on a dry basis. The char volume in the bed was assumed $9 \%$ of the total bed volume during the simulation modelling. The initial and boundary conditions are presented in Table 2 . The silica particle diameter in the range of 100-425 $\mu \mathrm{m}$ with an average diameter of $285 \mu \mathrm{m}$ was specified in the particle initial conditions. The formation of the tar and the higher hydrocarbons were neglected during this work.

The inflow of biomass is done by applying 'Particle feed: On' in the boundary conditions for the biomass. A pressure boundary was added at the top of the reactor to assist the outflow of the product gas. 'No particle exit' option was enabled in the pressure boundary condition to prevent the particles from passing through the pressure boundary. The reactor was set to a temperature of $1000 \mathrm{~K}$ initially as it takes considerable time to heat up the particles to the

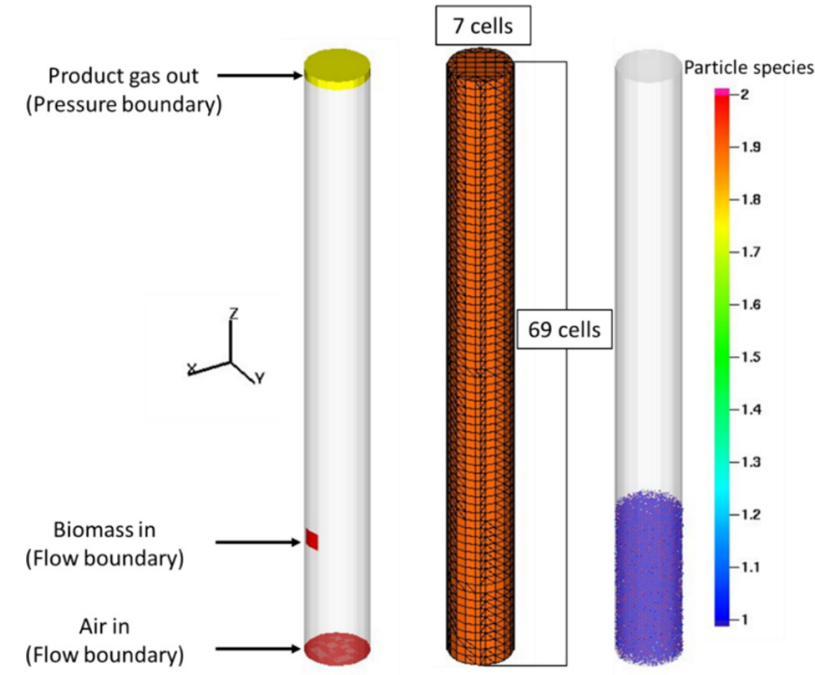

Figure 3: Schematic illustration of the barracuda model, (a) Boundary conditions, (b) Computational grid, (c) Initial particle in the bed (1-sand, 2- char). 
Table 2: Initial and boundary conditions.

\section{Initial conditions}

Fluid: air

- $1000 \mathrm{~K}$ and $101325 \mathrm{~Pa}$
Particle: silica

- $1000 \mathrm{~K}$ and $101325 \mathrm{~Pa}$

- Particle size: $100-425 \mu \mathrm{m}$

- 0.49 volume fraction

- Density $2650 \mathrm{~kg} / \mathrm{m}^{3}$

- $250 \mathrm{~mm}$ initial height fill
Particle: char

- $1000 \mathrm{~K}$ and $101325 \mathrm{~Pa}$

- Particle size: $500 \mu \mathrm{m}$ spherical

- 0.05 volume fraction

- Density $300 \mathrm{~kg} / \mathrm{m}^{3}$

- $250 \mathrm{~mm}$ initial height fill

\section{Boundary conditions}

\section{Air}

- $1000 \mathrm{~K}$ and $101325 \mathrm{~Pa}$

- $0.17 \mathrm{~m} / \mathrm{s}$

\section{Biomass}

- $500 \mathrm{~K}$ and $101325 \mathrm{~Pa}$

- Particle feed ON

- $2.08 \mathrm{~kg} / \mathrm{s}$
Product gas

- $101325 \mathrm{~Pa}$

- No particle exit

reactor temperature. The particle flow should be assisted by a fluid stream and the fluid volume flow can be adjusted by adjusting the slip velocity. Arrhenius reaction rate model was used for the reaction kinetics in the model. The reaction kinetics is presented in Table 3. The

Table 3: Reaction kinetics for air gasification [17-22].

Char partial oxidation

$2 \mathrm{C}+\mathrm{O}_{2} \leftrightarrow 2 \mathrm{CO}$

Char oxidation

$\mathrm{C}+\mathrm{O}_{2} \leftrightarrow \mathrm{CO}_{2}$

$\mathrm{CO}_{2}$ gasification $\mathrm{C}+\mathrm{CO}_{2} \leftrightarrow 2 \mathrm{CO}$

$\mathrm{H}_{2}$ oxidation

$\mathrm{H}_{2}+0.5 \mathrm{O}_{2} \leftrightarrow \mathrm{H}_{2} \mathrm{O}$

CO oxidation $\quad \mathrm{CO}+0.5 \mathrm{O}_{2} \leftrightarrow \mathrm{CO}_{2}$

$$
4.34 \times 10^{7} \mathrm{~m}_{\mathrm{s}} \operatorname{Texp}\left(\frac{-13590}{\mathrm{~T}}\right)\left[\mathrm{O}_{2}\right]
$$

$5.7 \times 10^{12} \mathrm{~m}_{\mathrm{s}} \exp \left(\frac{-4595}{\mathrm{~T}}\right)\left[\mathrm{O}_{2}\right]^{0.78}$

$1.12 \times 10^{8} \mathrm{~m}_{\mathrm{s}} \mathrm{P}^{0.31} \theta_{\mathrm{f}} \exp \left(\frac{-29518}{\mathrm{~T}}\right)\left[\mathrm{CO}_{4}\right]$

$5.69 \times 10^{11} \exp \left(\frac{-17610}{\mathrm{~T}}\right)\left[\mathrm{H}_{2}\right]\left[\mathrm{O}_{2}\right]^{0.5}$

$\mathrm{CH}_{4}$ oxidation $\quad \mathrm{CH}_{4}+1.5 \mathrm{O}_{2} \leftrightarrow \mathrm{CO}+2 \mathrm{H}_{2} \mathrm{O} 5.0118 \times 10^{11} \exp \left(\frac{-24357}{\mathrm{~T}}\right)\left[\mathrm{CH}_{4}\right]^{0.7}\left[\mathrm{O}_{2}\right]^{0.8}$

Water gas shift $\quad \mathrm{CO}+\mathrm{H}_{2} \mathrm{O} \leftrightarrow \mathrm{CO}_{2}+\mathrm{H}_{2} \quad 7.68 \times 10^{10} \mathrm{Texp}\left(\frac{-36640}{\mathrm{~T}}\right)[\mathrm{CO}]^{0.5}\left[\mathrm{H}_{2} \mathrm{O}\right]$

Methane reform- $\mathrm{CH}_{4}+\mathrm{H}_{2} \mathrm{O} \leftrightarrow \mathrm{CO}+3 \mathrm{H}_{2} \quad 3 \times 10^{5} \exp \left(\frac{-15042}{\mathrm{~T}}\right)\left[\mathrm{CH}_{4}\right]\left[\mathrm{H}_{2} \mathrm{O}\right]$
ing 
constants of the reaction rate kinetics for the major reactions were taken from the different sources available in the literature.

\section{RESULTS AND DISCUSSIONS}

\subsection{Experimental results}

The results of the temperature and the pressure measurements at the reactor wall (Sensor 3 in Fig. 2) of the bubbling bed during the experiment are presented in Fig. 4. The figure shows the temperature and pressure reading after $220 \mathrm{~min}$ from the start of the experiment.

The temperature and the pressure inside the gasification reactor are fluctuating because of different physical and chemical transformation. The temperature seems to be fluctuating more compared to the pressure in the reactor. This is mainly because of the irregular feeding of biomass through the screw conveyor. Irregular feeding of biomass changes the ER, thereby changing the reaction mechanism. High amount of biomass favours the partial oxidation, whereas low amount of biomass favours the complete oxidation, thereby increasing the reactor temperature. Uniform feeding is still challenging for systems handling wood chips in biomass gasification [23].

\subsection{Simulation model validation}

The average gas compositions from the simulation were compared with the experimental results, which are presented in Fig. 5. There is a good agreement between the experiments and the simulation results. The developed model was used to study the gasification process.

\subsection{Simulation results}

Simulations were performed for $100 \mathrm{~s}$, and the gas composition, gas temperature and gas flow rates were monitored. The average gas composition was taken as the time average composition for the final $50 \mathrm{~s}$ of the simulations. Fig. 6 shows the bed hydrodynamics in the gasifier after $100 \mathrm{~s}$ of simulation time. Fig. 6a shows that the reactor operates at the bubbling

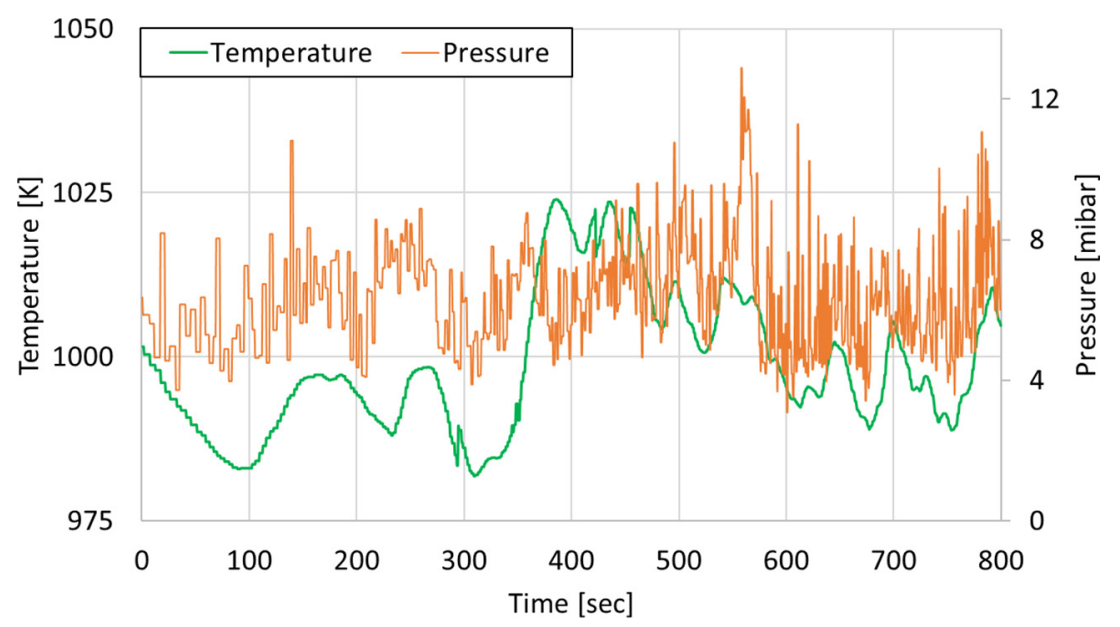

Figure 4: Temperature and pressure inside the reactor. 


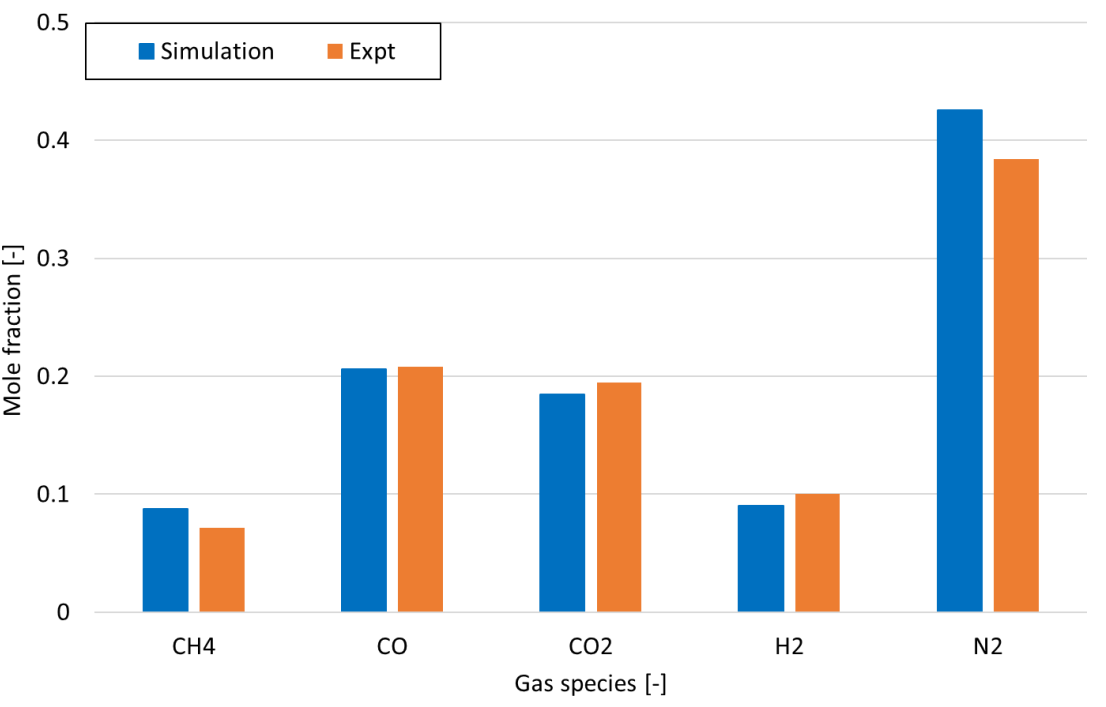

Figure 5: Average gas species for the experiment and the simulation.

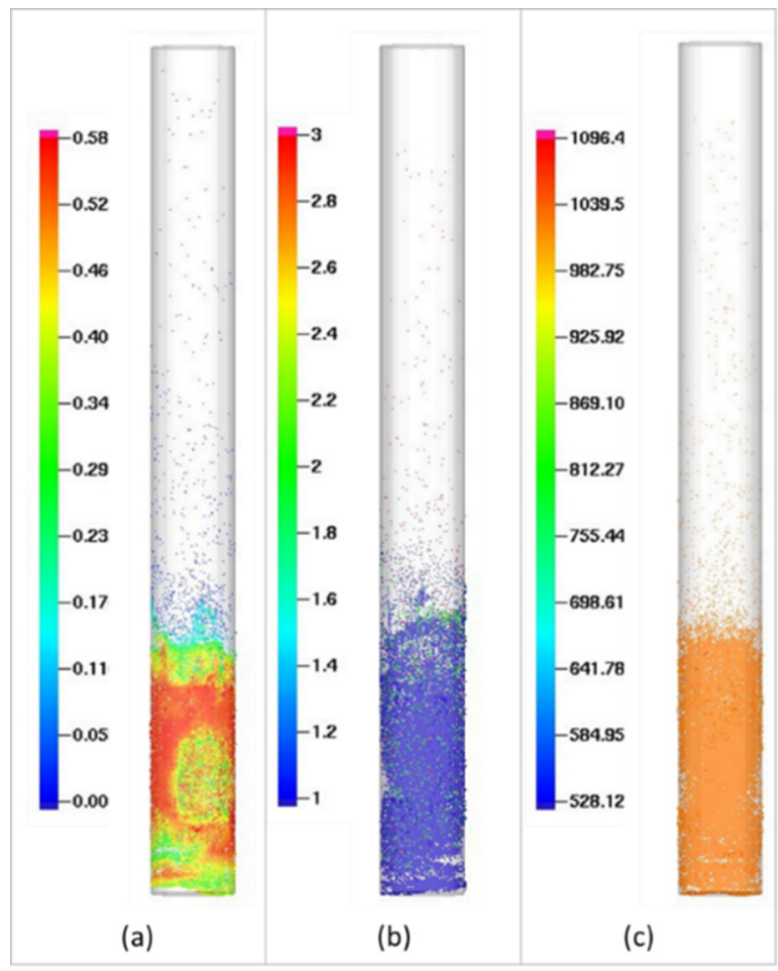

Figure 6: Bed hydrodynamics at $100 \mathrm{~s}$ : (a) particle volume fractions, (b) particle species distribution (1: sand, 2: char and 3: biomass) and (c) particle temperature (K). 
fluidization region with a few particles entrained in the freeboard region. The entrained particles in the freeboard region are mainly biomass particles and char because these particles have a low density compared to sand. Fig. $6 \mathrm{~b}$ shows the distribution of the different particle species in the bubbling fluidized bed. Blue particles depict the bed materials, green particles depicts the char inside the bed and the red particles depict the biomass particles. Fig. $6 \mathrm{c}$ shows the particle temperature distribution. Uniform particles temperature depicts the uniform mixing of the biomass and the sand particles. The reactor was continuously heated to supply the heat required for the gasification process, which slightly increases the reactor temperature with time.

The model was used to compare the product gas composition for different types of biomass as stated in Table 1. Fig. 7 shows the average product gas composition on a molar basis for olive waste, straw pellets and birch wood at $1000 \mathrm{~K}$.

Birch wood have the lowest hydrogen production and highest carbon monoxide production because of the low amounts of hydrogen and high amounts of $\mathrm{CO}$ in the pyrolysis gas composition. $\mathrm{CO}_{2}$ and $\mathrm{CH}_{4}$ production for straw pellets is very small compared to other biomasses. Along with the different combination of ER and biomass, the desired output product gas composition can be achieved.

Simulations were performed for different ER to see the product gas composition. ER is used to indicate the amounts of oxidizer in the reactor.

ER was adjusted with adjusting the biomass inflow into the reactor model, as the change in airflow would change the bed hydrodynamics and the particle/gas residence time. The stoichiometric air to fuel ratio was taken as 5.5 for the birch wood used during the experiments.

Fig. 8 depicts the product gas composition for the different $\mathrm{ER}$ at $1000 \mathrm{~K}$ for birch wood. The $\mathrm{CO}$ concentration decreased from 25 to 13.2 mole $\%$, whereas the $\mathrm{CO}_{2}$ concentration increased from 17 to 19.5 mole \% with change in ER from 0.15 to 0.3 . With same increase in ER, the nitrogen concentration increased by $38.5 \%$. With increasing ER, the process shifts towards combustion, as the amount of air (oxygen) increases. Fig. 8 shows the increase in $\mathrm{CO}_{2}$ concentration with increasing $\mathrm{ER}$. The $\mathrm{H}_{2}$ and $\mathrm{CH}_{4}$ concentration decreases slightly for the given range of ER.

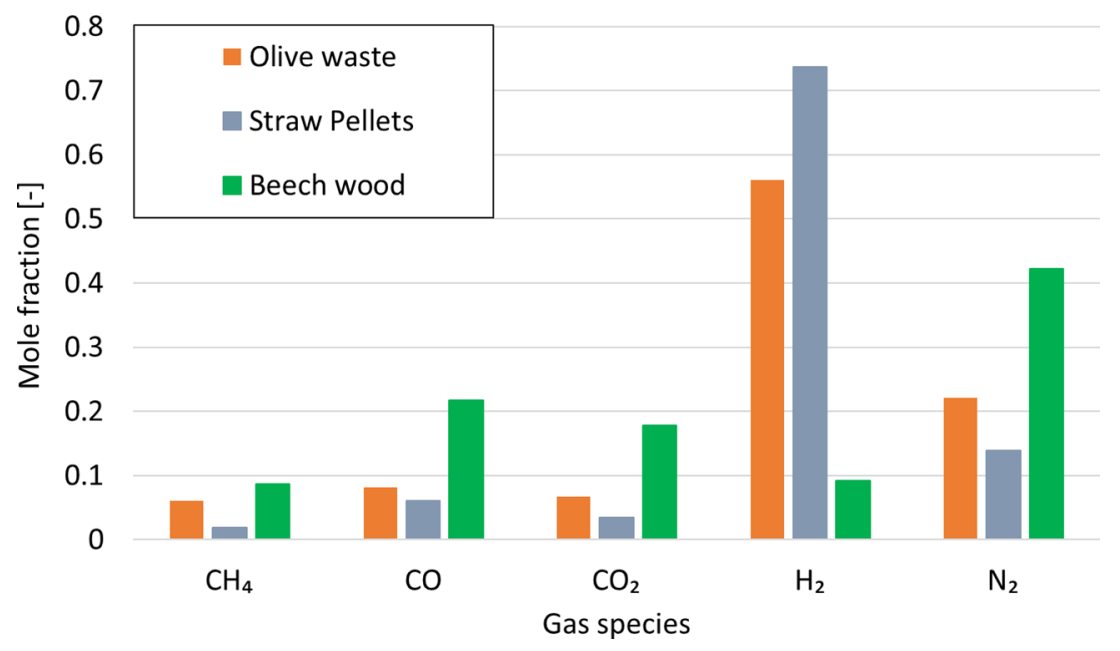

Figure 7: Product gas composition for different types of biomass. 


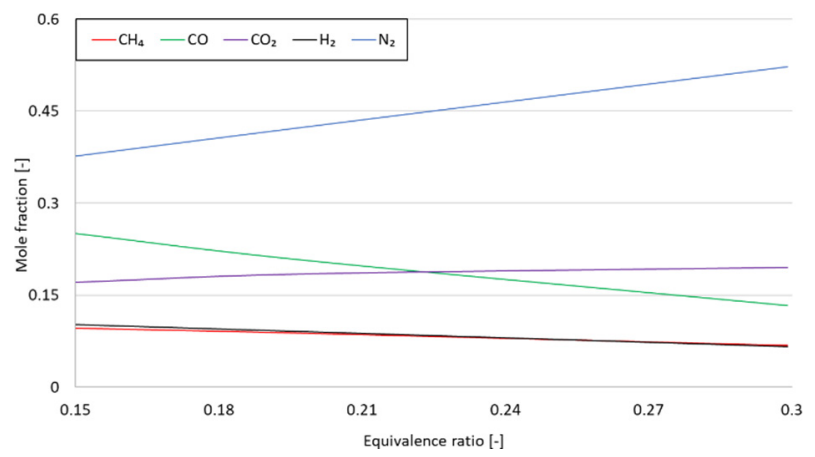

Figure 8: Product gas composition for different equivalence ratio.

The product gases were monitored during the simulation. Fig. 9 shows the composition of the product gas for birch wood over the simulation time.

The system reaches a steady state after around $15 \mathrm{~s}$ of simulation time. Fig. 9a shows the gas composition with respect to simulation time. The $\mathrm{CO}_{2}$ production increased abruptly after $2 \mathrm{~s}$. The high fraction of $\mathrm{CO}_{2}$ just after the start up represents the combustion process because of the excess oxygen present inside the reactor. Production of $\mathrm{CO}, \mathrm{H}_{2}$ and $\mathrm{CH}_{4}$ started gradually after $5 \mathrm{~s}$ of simulation time illustrates that the combustion process is gradually shifted towards gasification. The gas production rate at steady state fluctuates around its mean value because of the different physical and chemical transformations occurring inside the reactor. Fluctuations in the production of the gases are similar to the temperature fluctuations during the experiment as depicted in Fig. 4. Any industrial process is critical during the start-up and shut down process. It can be seen from Fig. $9 \mathrm{~b}$ that the temperature rises up to $1406 \mathrm{~K}$ just after the start up. This indicates that a gasification reactor should be able to withstand high temperatures.

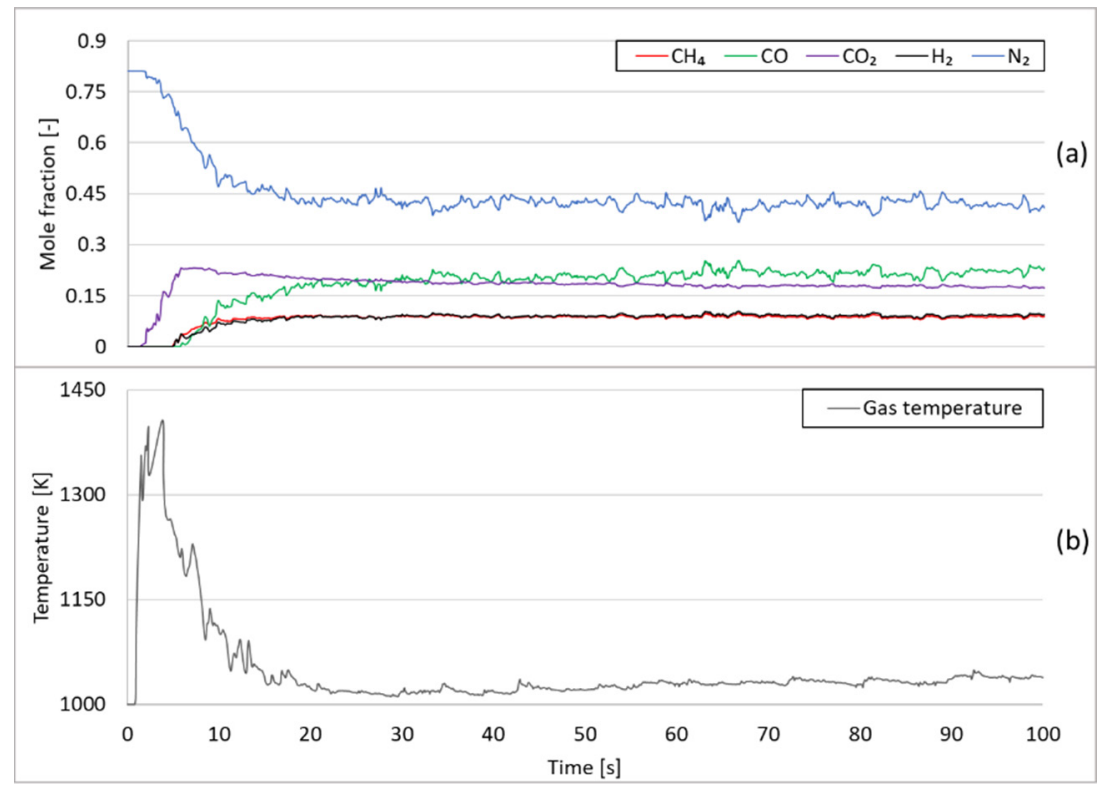

Figure 9: Product gas properties with respect to time: (a) mole fraction and (b) temperature. 
The average mass production rate of the product gas was found to be $0.0013 \mathrm{~kg} / \mathrm{s}$. As the product gas was produced at a high temperature, the ideal gas law was applied to calculate the gas production rate at normal temperature and pressure conditions $\left(25^{\circ} \mathrm{C}\right.$ and $\left.1 \mathrm{~atm}\right)$. The product gas flow rate was calculated as $1.96 \mathrm{Nm}^{3} / \mathrm{kg}$ of biomass. The volume production was found to be $0.144 \mathrm{Nm}^{3} / \mathrm{s} / \mathrm{m}^{2}$. The average gas compositions on the volume basis were 0.088 of $\mathrm{CH}_{4}, 0.207$ of $\mathrm{CO}, 0.186$ of $\mathrm{CO}_{2}, 0.091$ of $\mathrm{H}_{2}$ and 0.428 of $\mathrm{N}_{2}$, respectively. The lower heating value of the product gas was calculated as $6.65 \mathrm{MJ} / \mathrm{Nm}^{3}$.

\section{CONCLUSION}

Experiments were performed in a pilot-scale bubbling fluidized bed gasification reactor at the University of South-Eastern Norway. Birch wood chips were used for the experiments with air as a fluidizing agent. A model based on MP-PIC approach was developed and simulated using Barracuda ${ }^{\circledR}$. The average gas composition from the model was validated against the experimental results. The effect of ER and biomass feed on the performance of the gasifier was studied in this work. Gas composition, gas flow rate and lower heating value of the product gas were calculated for birch wood. The product gas composition varied with change in the biomass feed. The gasification process shifts towards the combustion process with the increase of the ER. For a case with birch wood, the CO concentration decreased from 25 to 13.2 mole \%, whereas the $\mathrm{CO}_{2}$ concentration increased from 17 to 19.5 mole \% when the ER increased from 0.2 to 0.3. During the start-up of the simulation, the gas temperature rises up to $1406 \mathrm{~K}$ implying that combustion is taken place. The process shifts gradually towards gasification with time. The gas temperature lies close to $1000 \mathrm{~K}$ during the steady-state operation. The simulation results give a good understanding of the air gasification of biomass in a bubbling fluidized bed gasification reactor. Along with the different experimental observation, the simulation works overcome the different issues related to biomass gasification using air as a fluidizing agent.

\section{REFERENCES}

[1] Hernández, J.J., Aranda-Almansa, G. \& Bula, A., Gasification of biomass wastes in an entrained flow gasifier: Effect of the particle size and the residence time. Fuel Processing Technology, 91(6), pp. 681-692, 2010. https://doi.org/10.1016/j.fuproc.2010.01.018

[2] Haryanto, A., Fernando, S.D., Pordesimo, L.O. \& Adhikari, S., Upgrading of syngas derived from biomass gasification: A thermodynamic analysis. Biomass and bioenergy, 33(5), pp. 882-889, 2009. https://doi.org/10.1016/j.biombioe.2009.01.010

[3] Bandara, J.C, Moldestad, B.M.E., \& Eikeland, M.S., Analysing the effect of temperature for steam fluidized-bed gasification of biomass with MP-PIC simulation, 9(6), pp. 529-542, 2018.

[4] Güell, B.M., Sandquist, J. \& Sørum, L., Gasification of biomass to second generation biofuels: a review. Journal of Energy Resources Technology, 135(1), p. 014001, 2013. https://doi.org/10.1115/1.4007660

[5] Bridgwater, A., The technical and economic feasibility of biomass gasification for power generation. Fuel, 74(5), pp. 631-653, 1995. https://doi.org/10.1016/00162361(95)00001-L

[6] Agu, C.E., Pfeifer, C., Eikeland, M., Tokheim, L.A. \& Moldestad, B.M., Detailed One-Dimensional Model for Steam-Biomass Gasification in a Bubbling Fluidized Bed. Energy \& Fuels, 33(8), pp. 7385-7397, 2019. https://doi.org/10.1021/acs. energyfuels.9b01340 
[7] Bin, C., Cong, W., Zhiwei, W., \& Liejin, G., Investigation of gas-solid two-phase flow across circular cylinders with discrete vortex method. Applied Thermal Engineering, 29(8-9), pp. 1457-1466, 2009. https://doi.org/10.1016/j.applthermaleng.2008.06.025

[8] Bandara, J.C., Eikeland, M.S., \& Moldestad, B.M.E., Analyzing the effects of particle density, size, size distribution and shape for minimum fluidization velocity with Eulerian-Lagrangian CFD simulation. Proceedings of the 58th SIMS Conference, pp. 60-65, 2017. https://doi.org/10.3384/ecp1713860

[9] Guo, X., Xiao, B., Liu, S., Hu, Z., Luo, S., \& He, M., An experimental study on air gasification of biomass micron fuel (BMF) in a cyclone gasifier. International Journal of Hydrogen Energy, 34(3), pp. 1265-1269, 2009. https://doi.org/10.1016/j. ijhydene.2008.11.107

[10] Lv, P.M., Xiong, Z.H., Chang, J., Wu, C.Z., Chen, Y. \& Zhu, J.X., An experimental study on biomass air-steam gasification in a fluidized bed. Bioresource technology, 95(1), pp. 95-101, 2004. https://doi.org/10.1016/j.biortech.2004.02.003

[11] Li, X.T., Grace, J.R., Lim, C.J., Watkinson, A.P., Chen, H.P. \& Kim, J.R., Biomass gasification in a circulating fluidized bed. Biomass and bioenergy, 26(2), pp. 171-193, 2004. https://doi.org/10.1016/S0961-9534(03)00084-9

[12] Dupont, C., Boissonnet, G., Seiler, J.M., Gauthier, P. \& Schweich, D., Study about the kinetic processes of biomass steam gasification. Fuel, 86(1-2), pp. 32-40, 2007. https:// doi.org/10.1016/j.fuel.2006.06.011

[13] Watkinson, A., Lucas, J. \& Lim, C., A prediction of performance of commercial coal gasifiers. Fuel, 70(4), pp. 519-527, 1991. https://doi.org/10.1016/0016-2361(91)90030-E

[14] Li, X., Grace, J.R., Watkinson, A.P., Lim, C.J. \& Ergüdenler, A., Equilibrium modeling of gasification: a free energy minimization approach and its application to a circulating fluidized bed coal gasifier. Fuel, 80(2), pp. 195-207, 2001. https://doi.org/10.1016/ S0016-2361(00)00074-0

[15] Yan, H.M., Heidenreich, C. \& Zhang, D.K., Mathematical modelling of a bubbling fluidised-bed coal gasifier and the significance of 'net flow'. Fuel, 77(9-10), pp. 10671079, 1998. https://doi.org/10.1016/S0016-2361(98)00003-9

[16] Timsina, R., Moldestad, B., Eikeland, M.S. \& Thapa R.K. Simulation of air-biomass gasification in a bubbling fluidized bed using CPFD model. Proceedings of the 60th SIMS Conference, pp. 145-150, 2020. https://doi.org/10.3384/ecp20170145

[17] Snider, D.M., Clark, S.M. \& O'Rourke, P.J., Eulerian-Lagrangian method for threedimensional thermal reacting flow with application to coal gasifiers. Chemical engineering science, 66(6), pp. 1285-1295, 2011. https://doi.org/10.1016/j.ces.2010.12.042

[18] Sreejith, C., Muraleedharan, C. \& Arun, P., Air-steam gasification of biomass in fluidized bed with $\mathrm{CO} 2$ absorption: A kinetic model for performance prediction. Fuel processing technology, 130, pp. 197-207, 2015. https://doi.org/10.1016/j.fuproc.2014.09.040

[19] Thapa, R., Pfeifer, C. \& Halvorsen, B.M., Modeling of reaction kinetics in bubbling fluidized bed biomass gasification reactor. Int. J. Energy Environment, 5, pp. 35-44.

[20] Bates, R.B., Ghoniem, A.F., Jablonski, W.S., Carpenter, D.L., Altantzis, C., Garg, A., Barton, J.L., Chen R. \& Field, R.P., Steam-air blown bubbling fluidized bed biomass gasification (BFBBG): Multi-scale models and experimental validation. AIChE Journal, 63(5), pp. 1543-1565, 2017. https://doi.org/10.1002/aic.15666 
[21] Xie, J., Zhong, W., Jin, B., Shao, Y., and Huang, Y., Eulerian-Lagrangian method for three-dimensional simulation of fluidized bed coal gasification. Advanced Powder Technology, 24(1), pp. 382-392, 2013. https://doi.org/10.1016/j.apt.2012.09.001

[22] Solli, K.-A., Thapa, R.K., and Moldestad, B.M.E., Screening of Kinetic Rate Equations for Gasification Simulation Models. Proceedings of The 9th EUROSIM Congress on Modelling and Simulation, EUROSIM 2016, The 57th SIMS Conference on Simulation and Modelling SIMS 2016, 142, pp. 105-112, 2018. https://doi.org/10.3384/ ecp17142105

[23] Svoboda, K., Pohořelý, M., Hartman, M., \& Martinec, J., Pretreatment and feeding of biomass for pressurized entrained flow gasification. Fuel processing technology, 90(5), pp. 629-635, 2009. https://doi.org/10.1016/j.fuproc.2008.12.005 